\title{
Biodegradative Threonine Dehydratase. Reduction of Ferricyanide by an Intermediate of the Enzyme-Catalyzed Reaction
}

\author{
Prasanta DATTA and Ranjan BHADRA \\ Department of Biological Chemistry, The University of Michigan
}

(Received June 20, 1978)

The threonine-dependent reduction of ferricyanide catalyzed by the purified biodegradative threonine dehydratase of Escherichia coli has been studied. The rate of production of 2-oxobutyrate in the presence of ferricyanide was lower than that found in the absence of ferricyanide. The concentrations of threonine required for half-maximal effects for the reduction of ferricyanide and, in the presence of the dye, for 2-oxobutyrate production, were $3 \mathrm{mM}$ and $9 \mathrm{mM}$, respectively. Reduction of ferricyanide was accompanied by evolution of $\mathrm{CO}_{2}$, and even within a very short incubation time with the enzyme, the ratio of ferricyanide reduced over $\mathrm{CO}_{2}$ evolved was approximately 7. Stopping the enzyme activity after a brief exposure to threonine at $\mathrm{pH} 9.7$ resulted in the accumulation of an intermediate (with a half-life of $4 \mathrm{~min}$ at $25^{\circ} \mathrm{C}$ ) which formed an adduct with $\mathrm{N}$-ethylmaleimide; the accumulated intermediate, in the absence of $\mathrm{N}$-ethylmaleimide, reduced ferricyanide with concomitant evolution of $\mathrm{CO}_{2}$. We conclude from these results that 2-aminocrotonate is the intermediate which serves as a source of reducing equivalent for ferricyanide, and nonstoichiometric amount of ferricyanide reduction may be attributed to some secondary reactions of ferricyanide with compounds derived from the oxidation product of 2-aminocrotonate.

With phenazine methosulfate and nitroblue tetrazolium, Feldberg and Datta [1] developed an activity stain for threonine dehydratase of Rhodospirillum rubrum on polyacrylamide gels. To explore the chemical basis for this activity stain, the reaction was studied spectrophotometrically using ferricyanide as an artificial electron acceptor. The results showed that in potassium phosphate buffer, $\mathrm{pH} 8.0$, the threonine-dependent reduction of ferricyanide was linear for approximately one minute and then decreased rapidly to a near-zero rate after the reduction of about $0.5 \mathrm{mM}$ ferricyanide. Neither the products of the dehydration reaction, 2-oxobutyrate and ammonia, nor the combination of products plus ferrocyanide affected the total amount of ferricyanide reduced $(0.5 \mathrm{mM})$ in the presence of enzyme and threonine. Furthermore, for every mole of ferricyanide reduced one mole of $\mathrm{CO}_{2}$ was generated. Based on these findings Feldberg and Datta [1] postulated that one of the intermediates of the threonine dehydratase

Enzymes. Biodegradative L-threonine dehydratase (EC 4.2.1.16); L-threonine dehydrogenase (EC 1.1.1.103); L-threonine aldolase or serine hydroxymethyltransferase (EC 2.1.2.1); D-aminopropanol dehydrogenase (EC 1.1.1.74). reaction [2], was serving as the electron donor. Using purified biodegradative threonine dehydratase of Escherichia coli we report that 2-aminocrotonate is the intermediate involved in the reduction of ferricyanide and that, once the intermediate has accumulated, reduction of ferricyanide can proceed in the absence of a functional dehydratase. In addition, we show that under certain conditions a large excess of ferricyanide can be reduced resulting in a nonstoichiometric amount of $\mathrm{CO}_{2}$ evolution and ferricyanide reduction.

\section{MATERIALS AND METHODS}

\section{Materials}

The following chemicals were purchased from Sigma Chemical Company: allo-free L-threonine, AMP, dithiothreitol, $N$-ethylmaleimide, $p$-hydroxymercuribenzene sulfonic acid (sodium salt) and 2amino-2-methyl 1,3-propandiol. Potassium ferricyanide was obtained from J. T. Baker. L-[U- $\left.{ }^{14} \mathrm{C}\right]$ Threonine was supplied by Amersham/Searle. All other chemicals were of reagent grade. 


\section{Enzyme Preparation}

Escherichia coli $\mathrm{K} 12$ was grown anaerobically at $37^{\circ} \mathrm{C}$ in tryptone/yeast extract medium supplemented with pyridoxine [3]. Biodegradative L-threonine dehydratase was purified by affinity chromatography on AMP-Sepharose column essentially by the method described for the Salmonella typhimurium enzyme by Bhadra and Datta [4]. Purity of enzyme preparations was checked routinely by polyacrylamide gel electrophoresis and was found to be greater than $95 \%$ pure. The purified protein was free from contaminating enzyme activities such as L-threonine dehydrogenase, D-aminopropanol dehydrogenase, and L-threonine aldolase.

\section{Assay Procedures}

Threonine dehydratase activity was measured either colorimetrically at $540 \mathrm{~nm}$ or spectrophotometrically at $310 \mathrm{~nm}$ as described [4] except that the phosphate buffer was replaced with propandiol buffer at $\mathrm{pH}$ values 8.0 and 9.7. The concentration of 2-oxobutyrate was determined from the absorption coefficients of $26.5 \mathrm{M}^{-1} \mathrm{~cm}^{-1}$ at $310 \mathrm{~nm}$ or of $4000 \mathrm{M}^{-1}$ $\mathrm{cm}^{-1}$ at $540 \mathrm{~nm}$.

The reduction of ferricyanide was measured at $420 \mathrm{~nm}$ according to Feldberg and Datta [1]; the amount of ferricyanide reduced was calculated from the absorption coefficient of $1000 \mathrm{M}^{-1} \mathrm{~cm}^{-1}$. To remove dithiothreitol, the enzyme solution was dialyzed exhaustively at $4^{\circ} \mathrm{C}$ against $0.1 \mathrm{M}$ potassium phosphate buffer, pH 6.8, containing $0.003 \mathrm{M} \mathrm{AMP.}$

The production of $\left[{ }^{14} \mathrm{C}\right] \mathrm{O}_{2}$ from ${ }^{14} \mathrm{C}$-labelled $\mathrm{L}$ threonine during ferricyanide reduction was measured in Thunberg tubes by the method described [1].

Protein was determined by the method of Lowry et al. [5] using bovine serum albumin as the standard.

\section{RESULTS}

\section{Reduction of Ferricyanide during Threonine Dehydration Reaction}

Fig. 1 depicts the reduction of ferricyanide and production of 2-oxobutyrate by the biodegradative $E$. coli threonine dehydratase at two $\mathrm{pH}$ values. Two important aspects of the results are worth summarizing. In propandiol buffer, $\mathrm{pH} \mathrm{8.0,} \mathrm{the} \mathrm{amount} \mathrm{of} \mathrm{2-}$ oxobutyrate produced in the absence of ferricyanide was linear with time, whereas, at $\mathrm{pH} 9.7$ there was a significant lag prior to steady-state rate of product formation (closed circles, Fig. 1). Similar lag at high $\mathrm{pH}$ value was observed by Feldberg and Datta [6] using threonine dehydratase of $R$. rubrum, and was attributed to a rapid accumulation of an intermediate

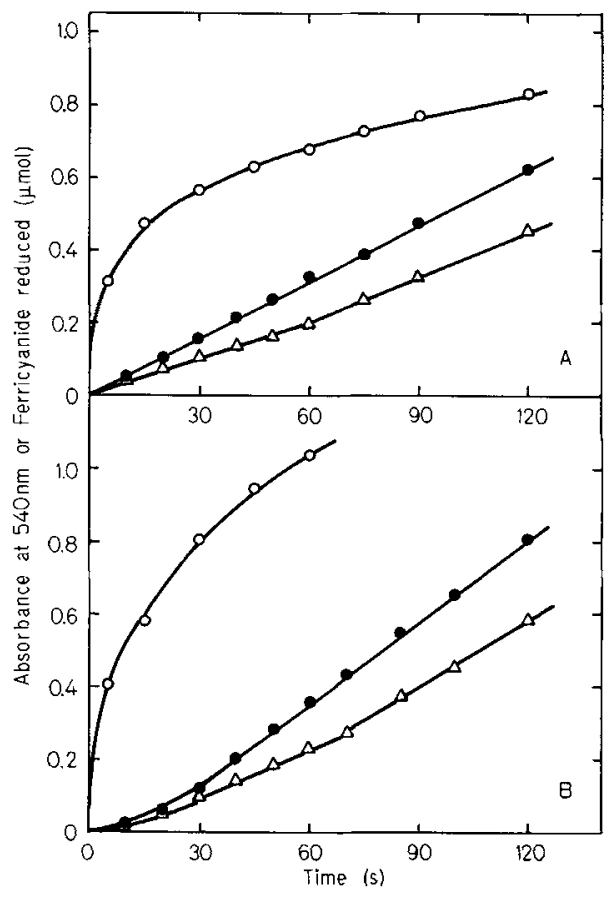

Fig.1. Time course of ferricyanide reduction and 2-oxobutyrate production. The reaction mixture, in a final volume of $1 \mathrm{ml}$, contained the following: propandiol buffer, $100 \mu \mathrm{mol}(\mathrm{pH} 8.0$ or pH 9.7); AMP, $3 \mu \mathrm{mol}$; L-threonine, $100 \mu \mathrm{mol}$; enzyme, $12 \mu \mathrm{g}$ protein; and potassium ferricyanide, $1.25 \mu \mathrm{mol}$, where indicated. For measurement of 2-oxobutyrate, 20 - $\mu$ l aliquots were withdrawn at specified times and mixed with the trichloroacetic acid/dinitrophenylhydrazine solution as described [3]; the data are expressed as absorbance at $540 \mathrm{~nm}$. The reduction of ferricyanide was followed by the decrease in absorbance at $420 \mathrm{~nm}$ using a Gilford recording spectrophotometer as described in Materials and Methods; the data are expressed as $\mu \mathrm{mol}$ of ferricyanide reduced. ( - , $\Delta-\Delta)$ 2-Oxobutyrate production in the absence or presence of ferricyanide, respectively. $(\mathrm{O}-\mathrm{O})$ Amount of ferricyanide reduced. (A) $\mathrm{pH} 8.0$; (B) $\mathrm{pH} 9.7$

of the threonine dehydration reaction having an absorbance maximum at $245 \mathrm{~nm}$. It was not possible to detect this intermediate by its spectral characteristics using $E$. coli dehydratase since the enzyme requires AMP for its catalytic activity which also has a high absorbance in the ultraviolet region of the spectrum.

When the amount of 2-oxobutyrate produced in the presence of ferricyanide was monitored (open triangles in Fig. 1), the rates of 2-oxobutyrate produced at both $\mathrm{pH}$ values in the presence of ferricyanide were lower than those seen without ferricyanide suggesting a competition for some intermediate(s) for the reduction of ferricyanide.

The data displayed in Fig. 2 on the reduction of ferricyanide and the production of 2-oxobutyrate in the presence of the dye as a function of L-threonine concentration show that both processes can be saturated with respect to threonine; the concentrations of threonine required for half-maximal effects for the reduction of ferricyanide and 2-oxobutyrate pro- 


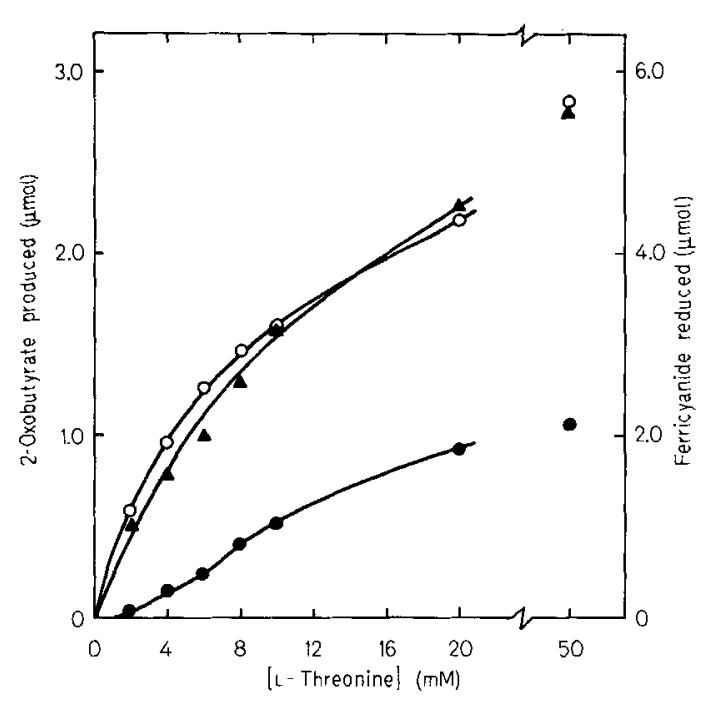

Fig. 2. Reduction of ferricyanide and 2-oxobutyrate production as a function of L-threonine concentration. The assay mixture contained, in a final volume of $1 \mathrm{ml}$, propandiol buffer, $\mathrm{pH} 9.7,100 \mu \mathrm{mol}$; AMP, $3 \mu \mathrm{mol}$; potassium ferricyanide, $20 \mu \mathrm{mol}$, where indicated; and $10 \mu \mathrm{g}$ of enzyme. The concentration of L-threonine was varied as shown. The reactions were carried out for $45 \mathrm{~s}$ at $25^{\circ} \mathrm{C}$ and the amount of 2-oxobutyrate produced and ferricyanide reduced were determined as described in Materials and Methods. (O-O) 2-Oxobutyrate produced in $\mu \mathrm{mol}$ in the presence and absence of ferricyanide, respectively; $(\Delta-\mathbf{\Delta})$ ferricyanide reduced in $\mu \mathrm{mol}$

duction were $3 \mathrm{mM}$ and $9 \mathrm{mM}$, respectively. In the presence of ferricyanide, the threonine saturation curve for 2-oxobutyrate production showed a sigmoidal relationship; this was not unexpected since, as discussed later, ferricyanide removed the intermediate more rapidly than the slower rate-limiting hydrolysis of the intermediate to form keto acid at high $\mathrm{pH}$.

\section{Accumulation of Intermediate and Reduction of Ferricyanide}

In order to explore the mechanism of ferricyanide reduction uncomplicated by the dehydratase reaction, purified enzyme was incubated at $25^{\circ} \mathrm{C}$ for $30 \mathrm{~s}$ in $0.1 \mathrm{M}$ propandiol buffer at $\mathrm{pH} 9.7$ containing $0.003 \mathrm{M}$ AMP and $0.05 \mathrm{M} \mathrm{L}$-threonine and the reaction was stopped by adding $0.005 \mathrm{M}$-hydroxymercuribenzene sulfonate, a potent inhibitor of threonine dehydratase activity. As mentioned earlier, a considerable accumulation of the intermediates of threonine dehydration reaction occurs during this time at this $\mathrm{pH}$. Addition of ferricyanide at various times after stopping the enzyme reaction resulted in a progressive decrease in the amount of ferricyanide reduced (Fig. 3); after 10 min at $25{ }^{\circ} \mathrm{C} 99 \%$ of the ferricyanide reduction was

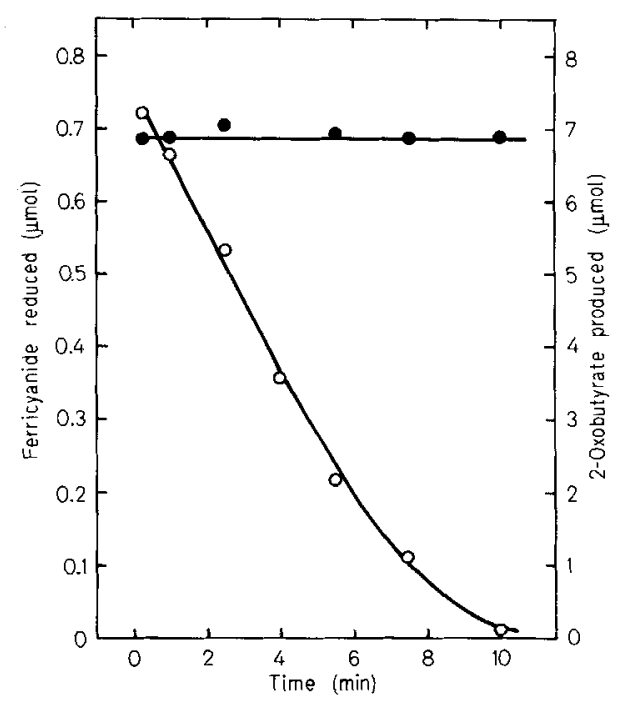

Fig. 3. Decreased amount of ferricyanide reduction as a function of time. In separate test tubes identical reaction mixtures containing propandiol buffer, $\mathrm{pH} 9.7$, AMP and L-threonine (see legend to Fig. 1) were incubated for $30 \mathrm{~s}$ at $25^{\circ} \mathrm{C}$ with $20 \mu \mathrm{g}$ of enzyme, and the reactions were stopped by adding $5 \mathrm{mM}$-hydroxymercuribenzene sulfonate. At time intervals indicated, one tube was withdrawn and the amount of ferricyanide reduced was measured spectrophotometrically after incubating with $1.25 \mathrm{mM}$ potassium ferricyanide for $10 \mathrm{~min}$; control experiments showed that ferricyanide reduction was complete within the 10 -min incubation period. An identical reaction mixture was employed to monitor the amount of 2-oxobutyrate produced at different time points following stopping the enzyme activity with the mercurial. $(\mathrm{O}-\mathrm{O})$ Reduction of ferricyanide; $(-\bullet)$ 2-oxobutyrate produced

abolished. Control experiment showed that the nonenzymatic production of 2-oxobutyrate from the intermediates at $\mathrm{pH} 9.7$ was slow and could not be detected during this time period as revealed by no further increase in 2-oxobutyrate production in the absence of ferricyanide. These data suggest that an intermediate accumulated at alkaline $\mathrm{pH}$, which serves as a reducing agent for ferricyanide, was being slowly converted to a product that did not react with ferricyanide and that time required in minutes for $50 \%$ conversion $\left(t_{1 / 2}\right)$ was about $4 \mathrm{~min}$ at $25^{\circ} \mathrm{C}$ at $\mathrm{pH} 9.7$. (In a similar experiment where the reaction mixture was kept at $4{ }^{\circ} \mathrm{C}$ following enzyme inactivation, the half-life of the intermediate was approximately $40 \mathrm{~min}$.) One additional fact emerged from these results: when the intermediate was allowed to accumulate the reduction of ferricyanide proceeded nonenzymatically.

\section{Trapping of the Intermediate by $\mathrm{N}$-Ethylmaleimide}

The proposed mechanism of threonine dehydration catalyzed by the threonine dehydratase of $E$. coli [2] involves elimination of $\alpha$-hydrogen and $\beta$-hydroxyl groups from the substrate to yield enzyme-bound 2- 


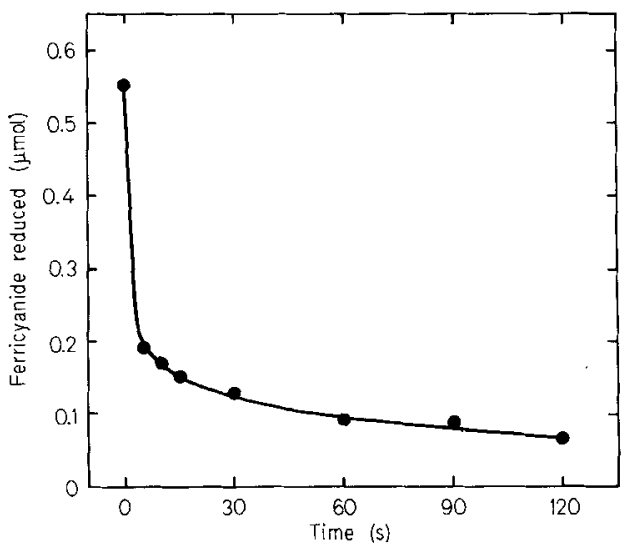

Fig. 4. Decreased extent of ferricyanide reduction in the presence of $\mathrm{N}$-ethylmaleimide. Threonine dehydratase $(20 \mu \mathrm{g}$ of protein) was allowed to react with L-threonine for $30 \mathrm{~s}$ at $25^{\circ} \mathrm{C}$ in propandiol buffer, $\mathrm{pH} 9.7$, containing $3 \mathrm{mM}$ AMP and the reaction was stopped by adding $p$-hydroxymercuribenzene sulfonate as described in the legend of Fig. 3. To separate but identical reaction mixtures described above, $5 \mathrm{mM}$ concentration of $N$-ethylmaleimide was added at different time intervals. All mixtures were incubated at $25^{\circ} \mathrm{C}$ for a total time period of $120 \mathrm{~s}$. At the end of this incubation time, the amount of ferricyanide reduced was measured following incubation with $1.25 \mathrm{mM}$ potassium ferricyanide for $10 \mathrm{~min}$. The time of incubation with $N$-ethylmaleimide, shown in the abscissa, represents the time, in seconds, the reaction mixture was in contact with maleimide prior to ferricyanide addition: Control experiments revealed that in 120 s only a $20 \%$ decrease of ferricyanide reduction was observed in the absence of maleimide

aminocrotonate which then tautomerizes to form 2iminobutyrate; the latter compound, free in solution, undergoes non-enzymatic hydrolysis to liberate ammonia and 2-oxobutyrate. Using the same enzyme from E. coli, Flavin and Slaughter [7,8] obtained conclusive evidence that inclusion of $N$-ethylmaleimide in the reaction mixture resulted in the formation of 2-oxo-3[3'-( $N^{\prime}$-ethyl-2',5'-dioxypyrrolidyl)]butyric acid due to addition of maleimide residue across the double bond of 2-aminocrotonate. The results depicted in Fig. 4 clearly show that nonenzymatic reduction of ferricyanide was blocked by $N$-ethylmaleimide. Incubation for $5 \mathrm{~s}$ with $\mathrm{N}$-ethylmaleimide of the reaction mixture after stopping the enzyme reaction prior to addition of ferricyanide decreased the amount of ferricyanide reduced by $65 \%$ of the control value; incubation for $120 \mathrm{~s}$, further lowered the amount of dye reduction by $90 \%$. Control experiment showed that without $N$-ethylmaleimide spontaneous hydrolysis of the intermediate in $120 \mathrm{~s}$ accounted for a decreased ferricyanide reduction by only $20 \%$ (cf. Fig. 3 ).

Addition of $N$-ethylmaleimide to the reaction mixture containing enzyme also blocked ferricyanide re-

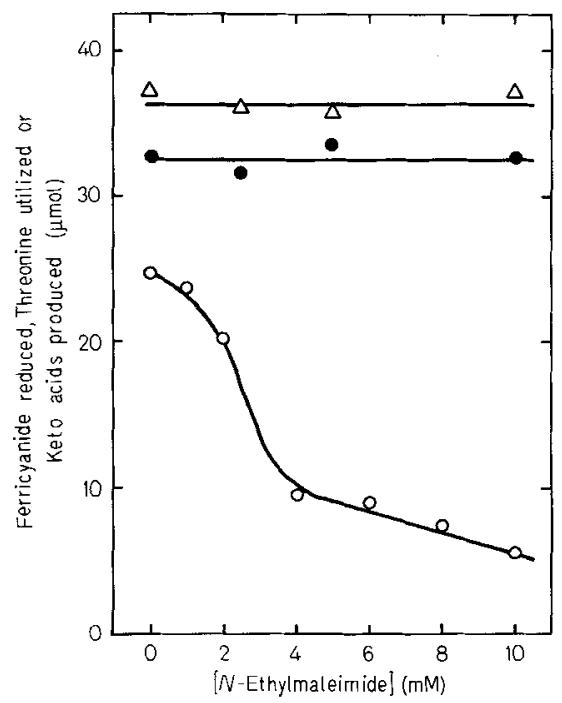

Fig.5. Effect of N-ethylmaleimide concentration on ferricyanide reduction during enzymatic reaction. Separate reaction mixtures containing $0.1 \mathrm{M}$ propandiol buffer, $\mathrm{pH} 9.7,3 \mathrm{mM}$ AMP, $50 \mathrm{mM}$ nonradioactive $\mathrm{L}$-threonine (or $\mathrm{L}-\left[\mathrm{U}-{ }^{14} \mathrm{C}\right]$ threonine), $50 \mathrm{mM}$ potassium ferricyanide and varying concentrations of $\mathrm{N}$-ethylmaleimide were incubated for $10 \mathrm{~min}$ at $25^{\circ} \mathrm{C}$ with $20 \mu \mathrm{g}$ of purified threonine dehydratase. The amount of ferricyanide reduced was determined spectrophotometrically after dilution of the reaction mixture. To measure the amount of threonine disappeared and the keto acids produced, aliquots of the reaction mixtures containing labeled threonine were spotted on Whatman No 1 filter paper and chromatographed as suggested [9]. The radioactive spots corresponding to L-threonine and 2-oxobutyrate plus the maleimide adduct of 2-aminocrotonate (after spraying a guide strip with ninhydrin and semicarbazide solutions) were cut out, eluted with water and counted for radioactivity. $(0-0)$ Ferricyanide reduced; $(\triangle-\Delta)$ threonine utilized; $(\bullet \bullet)$ keto acids produced

duction (Fig. 5). With increasing concentration of the reagent, progressively lower amount of ferricyanide was reduced, a result which may be explained by either trapping of 2-aminocrotonate by maleimide residues (as seen in Fig.4), or decreased production of the intermediate due to inhibition of threonine dehydratase activity by maleimide. To decide between these alternatives, the amount of ${ }^{14} \mathrm{C}$-labeled threonine utilized and the keto acids produced at several different concentrations of $\mathrm{N}$-ethylmaleimide were measured following separation by paper chromatography of the reaction products. These results, also included in Fig. 5, show that the amounts of threonine disappeared were the same in the presence or absence of maleimide; further, the amounts of total keto acids produced (2-oxobutyrate plus the maleimide adduct of 2-aminocrotonate), with or without $N$-ethylmaleimide were identical. In the particular solvent system used here, both 2-oxobutyrate and the maleimide adduct of 2 -aminocrotonate, migrated almost at the same position; the concentrations of these keto acids were calculated from their known structures and the specific radioactivity of threonine used as the substrate. In 
Table 1. Stoichiometry of ferricyanide reduced, 2-oxobutyrate produced and $\mathrm{CO}_{2}$ evolved as a function of ferricyanide concentration The experimental condition was identical to that described in the legend of Fig. 3. After addition of $p$-hydroxymercuribenzene sulfonate to stop the reaction, various concentrations of potassium ferricyanide were added. Following an incubation period of $10 \mathrm{~min}$ at $25^{\circ} \mathrm{C}$, the amount of ferricyanide reduced and 2-oxobutyrate produced were measured as described in Materials and Methods. For experiment II, $L-\left[\mathrm{U}-{ }^{14} \mathrm{C}\right]$ threonine was used as substrate, and the amount of $\mathrm{CO}_{2}$ evolved was measured as described [1]

\begin{tabular}{lllll}
\hline Expt & $\begin{array}{l}\text { Ferricyanide } \\
\text { added }\end{array}$ & $\begin{array}{l}\text { Ferricyanide } \\
\text { reduced }\end{array}$ & $\begin{array}{l}\text { 2-oxobutyrate } \\
\text { produced }\end{array}$ & $\begin{array}{l}\mathrm{CO}_{2} \\
\text { evolved }\end{array}$ \\
\hline & $\mu \mathrm{mol}$ & & & \\
& - & 0 & 6.98 & - \\
& 0 & 0.69 & - & - \\
& 1.25 & 1.14 & 6.29 & - \\
& 2.5 & 1.75 & 6.16 & - \\
I & 5.0 & 2.07 & 6.23 & - \\
& 12.5 & 2.10 & 6.10 & - \\
& 25.0 & 0.83 & - & 0.67 \\
II & 2.0 & 1.33 & - & 0.78 \\
& 5.0 & 2.05 & - & 0.98 \\
\hline
\end{tabular}

all cases, with or without maleimide, a slightly lower yield of the keto acids as compared to the amount of threonine disappeared was due to a small amount of radioactivity distributed throughout the paper and not included in the calculations.

From the cumulative results presented thus far, we conclude that $N$-ethylmaleimide was indeed trapping 2-aminocrotonate to form 2-oxo-3[3'-( $N^{\prime}$-ethyl$2^{\prime}, 5^{\prime}$-dioxypyrrolidyl)]butyric acid as shown by Flavin and Slaughter $[7,8]$ and that, in the absence of $N$ ethylmaleimide, 2-aminocrotonate was the reducing equivalent for the reduction of ferricyanide.

\section{Stoichiometry of the Ferricyanide Reduction Reaction}

Using purified enzyme from $R$. rubrum Feldberg and Datta [1] reported that for every mole of ferricyanide reduced one mole of $\mathrm{CO}_{2}$ was generated. When purified $E$. coli enzyme $(20 \mu \mathrm{g})$ was incubated for $30 \mathrm{~s}$ with $0.1 \mathrm{M}$ propandiol buffer, $\mathrm{pH} 9.7$, containing $3 \mathrm{mM}$ AMP, $100 \mathrm{mM} \mathrm{L}-\left[\mathrm{U}-{ }^{14} \mathrm{C}\right]$ threonine and $20 \mathrm{mM}$ ferricyanide, $1.1 \mu \mathrm{mol}$ of $\left[{ }^{14} \mathrm{C}^{-} \mathrm{O}_{2}\right.$ was liberated with concomitant reduction of $8.5 \mu \mathrm{mol}$ of ferricyanide; upon incubation for $5 \mathrm{~min}$, the amount of $\mathrm{CO}_{2}$ evolved was $1.6 \mu \mathrm{mol}$ whereas the total amount of ferricyanide present in the reaction mixture $(20 \mu \mathrm{mol})$ was completely reduced.

The data presented in Table 1 show that nonenzymatic reduction of ferricyanide (following addition of the dye after stopping the enzyme reaction with the mercurial) was also accompanied by $\mathrm{CO}_{2}$ evolution. It is of interest to note that with increasing concentration of the dye a progressively higher amount of ferricyanide was reduced (up to $2 \mu \mathrm{mol}$ ), whereas, the amount of $\mathrm{CO}_{2}$ evolved remained constant at about $1 \mu \mathrm{mol}$ with concomitant decrease in the yield of 2-oxobutyrate by the same amount (approximately $1 \mu \mathrm{mol})$. In separate experiments it has been ruled out that a significant amount of ferricyanide reduction may result from interaction of the dye with free 2oxobutyrate or by the nonenzymatic 'oxidation' of $\mathrm{L}$-threonine. We interpret these results to mean that the additional quantity of ferricyanide reduced may be due to some secondary reaction of ferricyanide with compounds derived from the oxidation product of 2-aminocrotonate. This notion is strengthened by the fact that upon paper chromatography [9] of the reaction mixture containing ferricyanide several fluorescent products as well as three nonfluorescent radioactive spots with relative mobilities of $0.26,0.40$ and 0.51 were seen. Starting with ${ }^{14} \mathrm{C}$-labeled L-threonine the major fluorescent material (relative mobility, 0.80 ) containing about $20 \%$ of input radioactivity in terms of threonine was purified. The compound has the following properties: $\lambda_{\max }=278-280 \mathrm{~nm}$, negatively charged, does not react with carbonyl reagents, contains $\mathrm{N}$ but no $\mathrm{NH}_{3}$ is released in hot alkali. The same fluorescent compounds as well as nonfluorescent radioactive spots were detected when potassium ferricyanide in the reaction mixture was replaced with the 2-electron acceptor dye, dichloroindophenol.

\section{DISCUSSION}

The results summarized above clarify two features of the threonine dehydration reaction catalyzed by the biodegradative threonine dehydratase of $E$. coli: the nature of the intermediate which accumulates when the enzyme is assayed at alkaline $\mathrm{pH}$, and the mechanism of threonine-dependent reduction of ferricyanide. Stopping the enzyme activity after a brief exposure to threonine at $\mathrm{pH} 9.7$ results in the formation of this intermediate which has a half-life at $25^{\circ} \mathrm{C}$ of about $4 \mathrm{~min}$; at $4^{\circ} \mathrm{C}$, the intermediate is more stable and decays with a half-life of about $40 \mathrm{~min}$. Addition of $N$-ethylmaleimide traps this material as a keto acid positive compound (as revealed by reactions with semicarbazide [9] and dinitrophenyl hydrazine) which fails to reduce ferricyanide. From several lines of evidence obtained with various enzymes catalyzing $\alpha, \beta$ elimination reactions (including threonine dehydratase), Falvin and Slaughter [8] have shown conclusively that 2 -aminocrotonate, and not 2 -iminobutyrate, reacts with maleimide to form an adduct 2-oxo-3-[3'-(N'-ethyl-2',5'-dioxypyrrolidyl)]butyric acid. We conclude that 2 -aminocrotonate is the intermediate which accumulates in solution during the dehydration of threonine and serves as a source of reducing equivalent for the reduction of ferricyanide. 
As seen with the enzyme from $R$. rubrum [1], the threonine-dependent reduction of ferricyanide by the. $E$. coli dehydratase was accompanied by evolution of $\mathrm{CO}_{2}$. However, with the E. coli enzyme the amount of ferricyanide reduced and $\mathrm{CO}_{2}$ evolved was not stoichiometric especially at high concentration of the dye. Thus, it is possible to argue that the ferricyanide reduction reaction may be distinct from that of dehydration of threonine catalyzed by the threonine dehydratase. To some extent it is true because the reduction of dye by the accumulated intermediate may proceed in the absence of active enzyme. Nevertheless, it is clear that a functional threonine dehydratase is needed to produce 2-aminocrotonate which reduces ferricyanide. Three separate lines of evidence confirm this notion: firstly the AMP-free form of the enzyme which shows very little catalytic activity toward threonine dehydration [10] also shows little activity for ferricyanide reaction, secondly, the apothreonine dehydratase (enzyme freed of pyridoxal phosphate coenzyme) does not catalyze either of these two reactions, and thirdly enzyme inactivated by serine and pyruvate [3] also failed to carry out ferricyanide reduction reaction.

We propose that 2-aminocrotonate is the enzymecatalyzed intermediate which serves as the electron donor for the reduction of ferricyanide and the nonstoichiometric amount of ferricyanide reduction may be attributed to some secondary reactions of the dye with compounds derived from the oxidation product of 2-aminocrotonate.

This work was supported by the United States National Institutes of Health grant GM-21436. We thank Dr C. V. Natraj for many stimulating discussions.

\section{REFERENCES}

1. Feldberg, R. S. \& Datta, P. (1970) Science (Wash. D.C.) 170 , 1414-1416.

2. Phillips, A. T. \& Wood, W. A. (1965) J. Biol. Chem. 240, 4703-4709.

3. Feldman, D. A. \& Datta, P. (1975) Biochemistry, 14, $1760-$ 1767.

4. Bhadra, R. \& Datta, P. (1978) Biochemistry, 17, 1691-1699.

5. Lowry, O. H., Rosebrough, N. J., Farr, A. L. \& Randall, R. J. (1951) J. Biol. Chem. 193, 265-275.

6. Feldberg, R. S. \& Datta, P. (1971) Eur. J. Biochem. 21, $438-$ 446.

7. Flavin, M. \& Slaughter, C. (1966) Biochemistry, 5, 1340-1350.

8. Flavin, M. \& Slaughter, C. (1969) J. Biol. Chem. 244, 14341444.

9. Magasanik, B. \& Umbarger, H. E. (1950) J. Am. Chem. Soc. $72,2308-2309$.

10. Phillips, A. T. \& Wood, W. A. (1964) Biochem. Biophys. Res. Commun. 15, 530-535.

P. Datta*, Department of Biological Chemistry, University of Michigan Medical School, Ann Arbor, Michigan, U.S.A. 48109

R. Bhadra, Department of Food Technology and Biochemical Engineering, Jadavpur University, Calcutta, India 700032

\footnotetext{
* To whom correspondence should be addressed.
} 